\title{
DNMT3A mutations and clinical features in Chinese patients with acute myeloid leukemia
}

\author{
Quanyi Lu*, Yamei Chen ${ }^{1}$, Hang Wang ${ }^{2}$ and Zhipeng $\mathrm{Li}^{1}$
}

\begin{abstract}
Mutations in DNA methyltransferase 3A (DNMT3A) gene were recently demonstrated in acute myeloid leukemia(AML). Approximately 20\% patients with AML carry DNMT3A gene mutations and was associated with a poor clinical outcome. but its clinical implications in Chinese AML patients are largely unknown. We analyzed 101 adult AML patients in china and found 14 patients (13.9\%) harboring this mutation. 9 patient with M5, 2 patients with M1, 2patient with M2 and 1 patient with M3. We identified 11 missense mutation,2 nonsense and $30 \mathrm{bp}$ deletion encompassing DNMT3A. The most common of them was predicted to affect 882Arg(in 4 patients). Double mutations were detected in two cases.10 of 33(43.5\%). DNMT3A mutations occurred more frequently in older (age $>50 y, p<0.05$ ) and the outcome is too badly for these patients. We concluded that DNMT3A mutations are highly recurrent in AML and is associated with distinct clinical and biologic characteristics and seems to be a useful as a prognostic marker.
\end{abstract}

Keywords: DNMT3A, Acute myeloid leukemia, Gene mutations

\section{Background}

Acute Myeloid Leukemia (AML) is a heterogeneous malignancy that can be classified by morphological, cytogenetic and molecular genetic criteria, Currently, cytogenetic analysis at diagnosis allows for risk-stratification of AML into a useful prognostic marker and intermediate risk [1], To some extent, Treatment protocols are adapted in an attempt to improve survival and decrease treatment-related toxicity. Unfortunately, prognostic implications have not been reliably established for AML in the intermediate risk category. In recent years, molecular analysis has identified novel markers with prognostic relevance in this diverse group. For example, AML with internal tandem duplication (ITD) in the fms-like tyrosine- kinase-3 gene (FLT3) carries a poor prognosis [2,3]. Molecular studies have pinpointed recurrent somatic mutations in NPM1, CEBP $\alpha$, TET2,MLL-PTD and fusion proteins such as PML-RAR $\alpha$ and CBFB-MYH11, which characterize specific types of AML [4].

The human DNA methyltransferase gene (DNMT1, DNMT3A and DNMT3B) encode enzymes which catalyze the addition of a methyl group to the fifth position of cytosine,generating 5 methylcytosine, by this mechanism, the DNA methyltransferase mediate the downregulation of target gene via the methylation of upstream CPG islands. Gene mutation in DNA methyltransferase which alter enzyme function have now been described in acute leukemia, Yamashita et al. reported [5] 4.1\% somatic mutation of DNA methyltransferase (DNMT3A) at amino-acid Arg882 in leukemia, Later Ley [6] et al. found 22.1\% DNMT3A mutations in adult normal karyotype AML genome and Chen SJ also discovered gene mutations in DNMT3A in patients with M5 (20.5\%) and with $13.6 \%$ of M4 subtype [7]. those results above indicated that DNMT3A mutations were independently and significantly associated with decreased survival in adult AML. in order to analyze the influence of DNMT3A mutation on the prognosis and survival of AML. In this study, RNA from bone marrow cells of untreated AML patients from the Chinese patients were examined by using PCR and sequence analysis, simultaneously chromosome examination and immunophenotype were also performed.

\footnotetext{
* Correspondence: quanyilu@hotmail.com
${ }^{1}$ Department of Haematology, Zhongshan Hospital of Xiamen University,

* Correspondence: quanyilu@hotmail.com
${ }^{1}$ Department of Haematology, Zhongshan Hospital of Xiamen University,

Xiamen 361004 , Fujian, China
Full list of author information is available at the end of the article

Xiamen 361004 , Fujian, China
Full list of author information is available at the end of the article
}

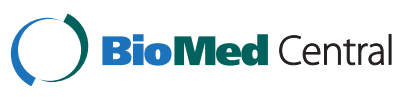

(c) 2013 Lu et al.; licensee BioMed Central Ltd. This is an Open Access article distributed under the terms of the Creative Commons Attribution License (http://creativecommons.org/licenses/by/2.0), which permits unrestricted use, distribution, and reproduction in any medium, provided the original work is properly cited. 


\section{Method}

\section{Patients and samples}

There were 101 patients aged 16-76 years with AML in this study, those were newly diagnosed AML which were classified according to French-American-British(FAB) classification system, including $M 0(n=2), M 1(n=4)$, M2( $n=41), M 3(n=25), M 4(n=6), M 5(n=21), M 6(n=2)$. All of them were diagnosed and treated in the Zhongshan Hospital of Xiamen University from July 2008 to Dec 2010. Bone marrow(BM) aspirates or peripheral blood $\left(\mathrm{PB} \mathrm{WBC}>50 \times 10^{9}\right)$ sample were collected at the first visit and in accordance with guidelines from the ethics committee of the hospital.

\section{Cytogenetic analysis}

Bone marrow cells were harvested directly before chemotherapy according to the study [8] , the metaphase chromosomes were banded by the G-banding techniques and karyotyped according to the International System for Human Cytogenetic Nomenclature.

\section{Immunophenotyping}

A panel of monoclonal antibodies to myeloid-associated antigens including CD13, CD14, CD33, as well as lymphoidassociated antigens including CD2, CD5, CD7, CD19, CD20, and lineage nonspecific antigens HLA-DR, CD34 were used to characterize the phenotypes of the leukemia cell with Epics XL4 flow cytometer (Beckman Coulter, America).

\section{RNA preparation}

Total RNA was isolated using RNAprep pure Blood Kit (Tiangen Biotech, China), according to the manufacturer's instructions,followed by treatment with RNase-free DNaseI to remove contaminating genomic DNA. The RNA was dissolved in RNase-free $\mathrm{H} 2 \mathrm{O}$, checked for purify and concentration with ND-1000 UV-vis Spectrophotometer (Nanodrop Technologies, USA) and stored at $-80^{\circ} \mathrm{C}$ until to be used.

\section{Reverse transcription PCR(RT-PCR)}

Reverse transcription was performed with T3 Thermocycle (Biometra, Germany), total RNA $(2 \mu \mathrm{g})$ was mixed with $10 \mathrm{mmol} \mathrm{dNTPs}$ and $25 \mathrm{pmol}$ random primers (TOYOBO, Japan), incubated at $65^{\circ} \mathrm{C}$ for 5 minutes, chilled immediately on ice, followed by addition of $20 \mathrm{U}$ RNase inhibitor, 1 RT buffer, $100 \mathrm{U}$ MMLV reverse transcriptase (Sangon, China) and RNase-free water to make up a volume of $20 \mu \mathrm{l}$. RT reaction was incubated at: $37^{\circ} \mathrm{C} 10$ minutes; $42^{\circ} \mathrm{C} 60$ minutes; $70^{\circ} \mathrm{C} 10 \mathrm{~min}$. Resultant complementary DNA (cDNA) was diluted with $180 \mu \mathrm{lddH} 2 \mathrm{O}(10 \mathrm{ng} / \mu \mathrm{l}$ RNA equivalent) and was stored at $-20^{\circ} \mathrm{C}$.

\section{Mutation analysis}

The DNMT3A was amplified by 2 pairs of primers and sequenced by the same ones. The sequences of these PCR and sequencing primers are F1: 5'-GCCACCAGAAGAA GAGAAGAATCC-3',R1: 5'-CTCTTCTGGGTGCTGATA CTTCT-3,'F4: 5'-CTCGCCTCCAAAGACCACG-3',R3: 5'TTCTCCGCTGTGCTCTTCC-3'.

The reference sequence was NM_022552.3 for mRNA. In every $25 \mu \mathrm{L}$ of PCR reaction, there were $1 \mathrm{SSP}$ buffer (67 mM Tris-HCl, $16 \mathrm{mM}$ (NH4)2SO4, 0.01\% Tween 20, pH 8.8), $0.2 \mathrm{mM}$ dNTPs, $2.5 \mathrm{mM} \mathrm{MgCl} 2,0.4 \mathrm{uM}$ each tagged primer, $0.5 \mathrm{U}$ TaqHS DNA polymerase (Takara, Japan), and $5 \mu \mathrm{l}$ of cDNA. The amplification was performed in a Thermal Cycler PCR instrument (Bioer, China) under the following conditions: $95^{\circ} \mathrm{C}$ 3 minutes; 10 cycles of touchdown PCR, $95^{\circ} \mathrm{C} 20$ seconds, $65^{\circ} \mathrm{C}-60^{\circ} \mathrm{C}$ (decreased by $0.5^{\circ} \mathrm{C}$ per cycle) 20 seconds, $72^{\circ} \mathrm{C} 90$ seconds; 30 cycles of $95^{\circ} \mathrm{C} 20$ seconds, $60^{\circ} \mathrm{C}$ 20 seconds, $72^{\circ} \mathrm{C} 90$ seconds and finally, $72^{\circ} \mathrm{C} 7 \mathrm{~min}$. The PCR products were verified by electrophoresis and sequencing. Clone the DNA fragments with overlap peak into pMD18-T vector (Takara, Japan) and sequencing. When the mutations were not obvious because of location near the primers,sequencing from the other direction was done to solve this issue.

\section{Statistical analysis}

The discrete variables of patients with and without gene mutation were compared using the $\chi^{2}$ tests, but if the theoretical frequency was smaller than 5,correction for continuity was used All statistical analyses were performed with SPSS 16.0 software(SPSS Inc).

\section{Results}

\section{DNMT3A mutations}

In my study, 101 samples from new diagnostic AML were detected by PCR amplification of entire coding region of DNMT3A, the detection rate of DNMT3A mutations in AML patients was 13.9\%(14/101), including 2 patients of M1, 2 patients of M2,1 patient of M3 and 9 patients of M5(42.9\%). (Table1) the type of mutations was 11 missense, 2 nonsense and 1 deletion mutations.respectively. single nucleotide variations included $2645 \mathrm{G}>\mathrm{A}$ (Arg882His), $914 \mathrm{G}>\mathrm{A}$ (nonsense), $2096 \mathrm{G}>\mathrm{A}($ Gly699Asp), 2501C > T(Thr834IIe), 55C > T(Arg19Trp), 2202C > A(Phe734Leu) and 2644 C > $\mathrm{T}$ (Arg882Cys).(,Fig-1) The most common mutations are predicted to affect amino- acid Arg882 (in 6 patients) and Thr834(in 2 patients).We also detected a 30 bp deletion according to sequencing (Figure 1, patient 40). Double point mutation was also detected in 2 patient (Figure 2). DNMT3A mutation (2645 G > A) was found in BM sample of the old patient with M5, this is the same with that of Ewalt reported (Figure 1 patient 77) [9]. 
Table 1 Clinical features of the Patients with DMNT3A mutations

\begin{tabular}{|c|c|c|c|c|c|c|c|c|c|}
\hline No & Age & sex & FAB & Cytogenetics & WBC X10^9/L & CD33+/CD34+ & DNMT3A & Chemo-response & result \\
\hline 7 & 65 & $\mathrm{~F}$ & M1 & normal & 36.6 & $6 \% / 92 \%$ & $2645 \mathrm{G}>\mathrm{A}$ & $C R$ & $\operatorname{Dead}(12 \mathrm{M})$ \\
\hline 19 & 72 & M & M2 & normal & 57.2 & $99 \% / 32 \%$ & $914 \mathrm{G}>\mathrm{A}$ & No & $\operatorname{Dead}(6 \mathrm{M})$ \\
\hline 22 & 55 & M & M5 & normal & 112.9 & $99 \% / 16 \%$ & $2645 \mathrm{G}>\mathrm{A}$ & $C R$ & Alive(SCT) \\
\hline 38 & 58 & $\mathrm{~F}$ & M5 & $t(6 ; 9)$ & 12.1 & $56 \% / 55 \%$ & 2096 G > A & $C R$ & $\operatorname{Dead}(10 \mathrm{M})$ \\
\hline 40 & 56 & $\mathrm{~F}$ & M2 & $\operatorname{inv}(9)$ & 15 & $20 \% / 82 \%$ & 30 bp del 2502-2531 & $C R$ & Dead(SCT) \\
\hline 47 & 31 & $\mathrm{~F}$ & M5 & del(13) & 1.5 & $95 \% / 27 \%$ & $2501 C>T$ & NO & $\operatorname{Dead}(3 \mathrm{M})$ \\
\hline 48 & 20 & $\mathrm{~F}$ & M5 & normal & 30.4 & $4.5 \% / 71 \%$ & $2501 C>T$ & NO & $\operatorname{Dead}(3 \mathrm{M})$ \\
\hline 53 & 53 & $\mathrm{~F}$ & M3 & $t(4 ; 17)$ & 7.9 & $82 \% / 1.6 \%$ & $55 \mathrm{C}>\mathrm{T}$ & $C R$ & Alive \\
\hline 56 & 54 & $\mathrm{~F}$ & M5 & normal & 2.19 & $95 \% / 28 \%$ & 2202 C > A & $C R$ & Relapse(6 M) \\
\hline 68 & 52 & M & M5 & normal & 28.8 & $97 \% / 42 \%$ & $2644 C>T$ & No & $\operatorname{Dead}(6 \mathrm{M})$ \\
\hline 77 & 76 & M & M5 & normal & 67 & No & 2645 G > A Arg882His & $C R$ & $\operatorname{Dead}(13 \mathrm{M})$ \\
\hline 89 & 76 & M & M1 & normal & 17.3 & CD13 CD34 & 1906 G > A 2191 T>C & NR & $\operatorname{Dead}(3 \mathrm{M})$ \\
\hline 94 & 61 & $\mathrm{~F}$ & M5 & normal & 132 & CD7CD13CD33 & $2141 C>G$ & NO & $\operatorname{Dead}(1 \mathrm{M})$ \\
\hline 100 & 46 & M & M5 & normal & 4.5 & CD13CD34 & $1792 C>T 2375 G>A$ & NR & $\operatorname{Dead}(1 \mathrm{M})$ \\
\hline
\end{tabular}

$C R$ Complete remission, No no chemotherapy, $N R$ not remission, $M$ month.

\section{Clinical features of DMNT3A mutation positive patients} Of the mutated patients, AML-M5 subtype had higher DNMT3A mutation rate than those with other subtype. Cytogenetic data showed that 10 cases with DNMT3A mutation was normal karyotypes AML patients (71.45\%, $\mathrm{p}>0.05)$. No DNMT3A mutations were found in AML samples with cytogenetic findings associated with a favorable (except 1 patient with M3). In all of positive patients,
8 patients were female $(57.1 \%, \mathrm{p}>0.05), 11$ patients were older than 50 years $(78.6 \%, \mathrm{p}<0.05)$. we also discovered that DNMT3A mutations were associated with high expression of CD33 or CD34, After having been treated by induction chemotherapy, all patients achieved complete hematological remission(76.5\%), but 4 patients refused to receive chemotherapy, after 12 monthes follow up, only 2 patients were alive including 1 M3 patient.

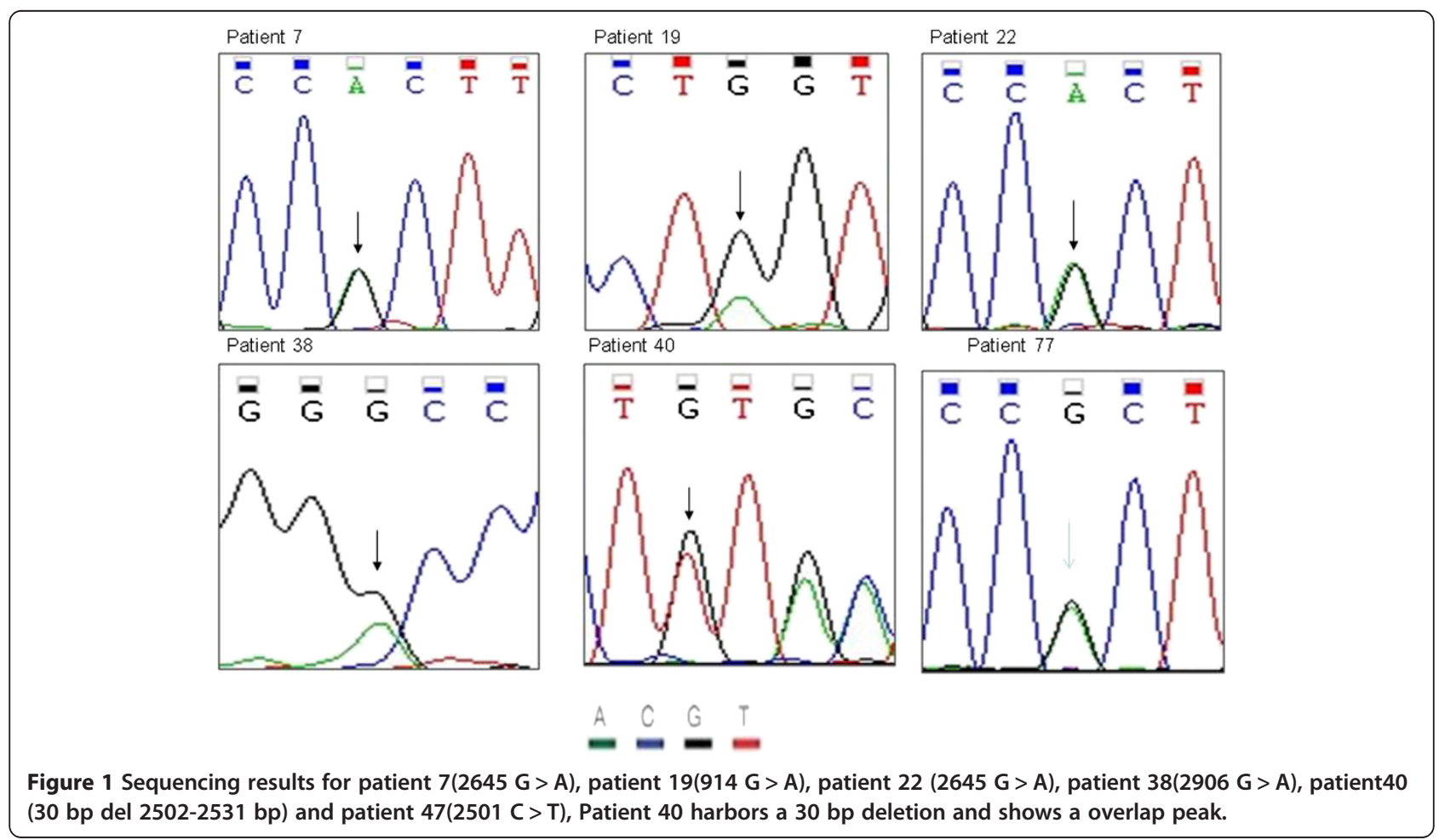




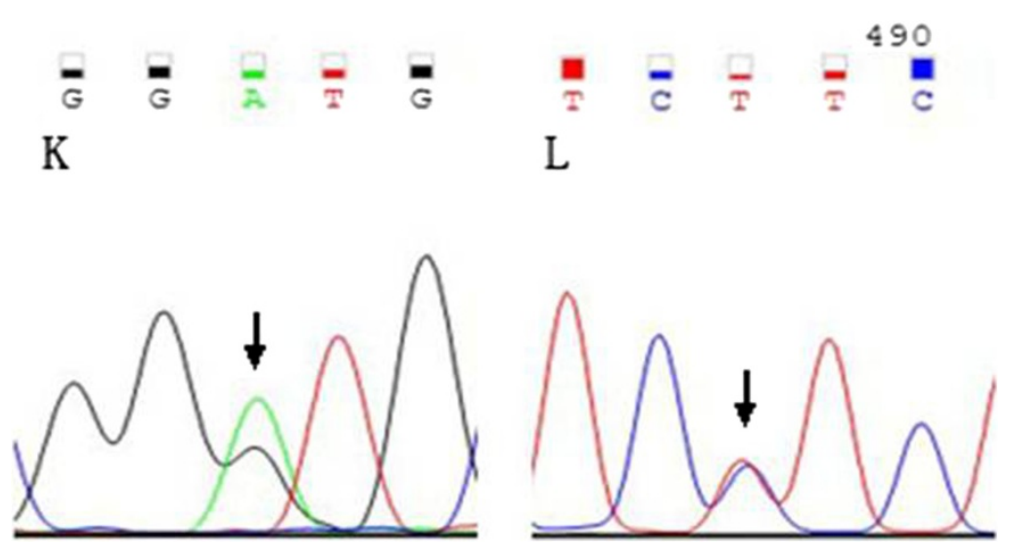

Figure 2 Sequencing results for patient 89, the double point DNMT3A mutation was K: 1906 G > A,L:2191 T > C.

\section{Discussion}

Epigenetic mechanisms play a crucial role in regulation of gene expression and DNA methylation catalyzed by specific DNA methyltransferase and DNMTs is an important epigenetic control of gene expression and the maintenance of genome integrity. Many DNMTs appear to be present in human and have a different role in establishing and maintaining the DNA methylation pattern including DNMT1, DNMT2, DNMT3A, DNMT3B and DNMT3L $[10,11]$. DNMT1 is the primary enzyme responsible for copping methylation patterns after DNA replication while DNMT2 does not methylate DNA but instead methylates small RNA,. DNMT3A and DNMT3B are paralogous enzymes responsible for de novo DNA cytosine methylation. DNMT3L plays a key role in allowing DNA methylation during the maturation of germ [12]. Mouse studies showed that DNMT is required for hematopoietic stem cell self renewal, regulation of proliferation and normal myeloid and lymphoid differentiation. By contrast, deletion of DNMT3A and DNMT3B in mouse hematopoietic stem cells impaired stem cell self renewal, the frequent DNMT3A mutations may be an parts of pathogenesis in acute myeloid leukemia [13].

In this study, we report the frequency of DNMT3A mutations in patients with de novo AML and their Clinical features compared to the patients without DMNT3A mutations. We sequenced all coding exon of DNMT3A using DNA from leukemia cells and identified 14 heterozygous mutations (13.9\%). Amino acid R882, located in the methyltransferase domain of DNMT3A, was the most common mutation site. Our results showed that the rate of DNMT3A gene mutations in Chinese AML patient is more common and AML-M5 was more higher than other type(9/21) the alterations of Arg882 are also the most frequent mutation in Chinese AML patients. We also found one AML-M3 patient who carried $t(4 ; 17)$ chromosomal abnormality carry DNMT3A gene mutation and this is not reported by other papers [6,7].

Our results indicated that most of patients(11/14) with DNMT3A mutation died of leukemia after 6 months treatment, two patient were alive due to allogeneic stem cell transplant and AML-M3 type. The last one was one relapse. Although it is unclear if DNMT3A mutation can affect survival of AML patient, this fact was accord with concept that DNMT3A mutation could be a dependent factor on AML patients. In concurrence with other reporters, there was no significant association between DNMT3A mutations and sex, high WBC or increased blast percentage in the bone marrow at diagnosis. But the high expression of CD33 or CD34 on AML cells was very common., DNMT3A mutation were found in patients above 50 years of age, this is agreement with previous studies. Although DNMT3A gene mutation was almost never found in AML-M3 subtype, this patient carried $t(4 ; 17)$ chromosomal abnormality and PML-RAR $\alpha$ fusion gene, it may be associated with a poor prognosis for no-classical acute promyelocytic leukemia.

To conclude, it seems that DNMT3A mutations are consistently present in approximately $10 \%$ of AML cases, the role of DNMT3A mutations on leukemogenesis was still unclear. Future studies will help to illuminate the pathogenesis of AML, we need to develop a method of quick determination of the whole gene mutations and evaluate the influence of DNMT3A mutation on treatment response and survival in a larger sample.

\section{Competing interest}

The authors declare no financial or commercial conflict of interest.

\section{Authors' contributions}

Dr Quanyi Lu organized the research plan, Dr Yamei Chen analyzed data, performed experiments and drafted the paper. and Dr zhipeng Li and Prof Hang Wang coordinated the study, participated in its design and

contributed to writing. All authors read and approved the final manuscript. 


\section{Acknowledgment}

We want to thank Dr Jiangning Zhao, Dr Jiasheng Hu,they provided blood or bone marrow sample and medical care for those patients at Zhongshan Hospital of Xiamen University.

This work was partially supported by the "985" Program of Medical College of Xiamen University.

\section{Author details}

'Department of Haematology, Zhongshan Hospital of Xiamen University, Xiamen 361004, Fujian, China. ${ }^{2}$ Department of Biomedical Sciences and the Key Laboratory of the Ministry of Education for Cell Biology and Tumor Cell Engineering, School of Life Sciences, Xiamen University, Xiamen, Fujian, China.

Received: 24 September 2012 Accepted: 8 January 2013

Published: 11 January 2013

\section{References}

1. Tara K, Gregory DW, Chen $Y$, et al: Molecular prognostic markers for adult acute myeloid leukemia with normal cytogenetics. J Hematol Oncol 2009, 2:23.

2. Levis M, Small D: FLT3 ITDoes matter in leukemia. Leukemia 2003, 17:1738-1752.

3. Gilliland DG, Griffin JD: The roles of FLT3 in hematopoiesis and leukemia. Blood 2002, 100:1532-1542.

4. Tefferi A: Novel mutations and their functional and clinical relevance in myeloproliferative neoplasms: JAK2, MPL, TET2, ASXL1, CBL, IDH and IKZF1. Leukemia 2010, 24(6):1128-38.

5. Yamashita Y, Yuan J, Suetake I, et al: Array-based genomic resequencing of human leukemia. Oncogene 2010, 29:3723-3731.

6. Ley TJ, Ding L, Walter MJ, et al: DNMT3A Mutations in Acute Myeloid Leukemia. N Engl I Med 2010, 363:2460-2461.

7. Yan XJ, Xu J, Gu ZH, et al: Exome sequencing identifies somatic mutations of DNA methyltransferase gene DNMT3A in acute monocytic leukemia. Nat Genet 2011, 13(4):309-315.

8. Tien HF, Wang CH, Lin MT, et al: Correlation of cytogenetic results with immunophenotype, genetype, clinical features, and ras mutation in acute myeloid leukemia: a study of 235 Chinese patients in Taiwan. Cancer Genet Cytogenet 1995, 84:60-68.

9. Ewalt M, Galili NG, Mumtaz M, et al: DNMT3A mutations in high-risk myelodysplastic syndrome parallel those found in acute myeloid leukemia. Blood Cancer J 2011, 1(3):e9.

10. Jaenisch R, Bird A: Epigenetic regulation of gene expression: how the genome integrates intrinsic and environmental signals. Nat Genet 2003, 33:245-254.

11. Ling Y, Sankpal UT Robertson AK, et al: Modification of de novo DNA methyltransferase 3a (Dnmt3a) by SUMO-1 modulates its interaction with histone deacetylases (HDACs) and its capacity to repress transcription. Nucleic Acids Res 2004, 32:598-610.

12. Tang $M, X u$ W, Wang $Q$, et al: DNMT and its Epigenetic Regulation for Lung Cancer Therapy. Curr Genomics 2009, 10:336-52.

13. Trowbridge JJ, Snow JW, Kim J, et al: DNA methyltransferase 1 is essential for and uniquely regulates hematopoietic stem and progenitor cells. Cell Stem Cell 2009, 2(4):442-449.

\section{Submit your next manuscript to BioMed Central and take full advantage of:}

- Convenient online submission

- Thorough peer review

- No space constraints or color figure charges

- Immediate publication on acceptance

- Inclusion in PubMed, CAS, Scopus and Google Scholar

- Research which is freely available for redistribution 